\title{
La ética pública en tiempos de crisis (XXIV Conferencias Aranguren)
}

\section{Public ethics in times of crisis (xxIV Aranguren Lectures)}

\author{
ELISA PÉREZ VERA \\ Catedrática emérita, UNED
}

\begin{abstract}
REsumen. Desde hace unos años, la palabra crisis se ha instalado en nuestro lenguaje cotidiano. Se trata de un término polivalente que se aplica sobre una realidad magmática de contornos imprecisos. Inicialmente la crisis se manifestó a nivel económico. Pero la crisis afecta al disfrute de los derechos constitucionales, agravando el desamparo de una ciudadanía cada vez más alejada de la clase política. En este contexto, la corrupción política detrae una cuantía escandalosa recursos que podrían ser destinados a satisfacer derechos constitucionales. De ahí que la lucha contra la corrupción resulte prioritaria. Los códigos éticos aparecen como nuevos instrumentos de regeneración de la vida pública con los que romperla judicialización de la vida política, que tanto daño están causando a nuestro sistema democrático.
\end{abstract}

Palabras clave: crisis; derechos constitucionales; corrupción; códigos éticos.
AbSTRACt. Since some years, the word crisis has been installed in our everyday language. It is a versatile term that is applied to a magmatic reality of vague outlines. Initially the crisis manifested itself economically. But the crisis affects the enjoyment of constitutional rights, aggravating the distress of an increasingly distant citizenship from the political class. In this context, political corruption diverts an outrageous amount of resources that could be destined to satisfy constitutional rights. Hence the fight against corruption resulting priority. Ethical codes appear as new instruments for the regeneration of public life that break the judicialization of political life, which are causing so much damage to our democratic system.

Key words: crisis; constitutional rights; corruption; ethical codes.

\section{PRESENTACIÓN}

De manera obligada, mis primeras palabras han de ser de agradecimiento al Instituto de Filosofía del CSIC y a su directora, Concha Roldán, por invitarme a impartir las charlas correspondientes a esta nueva edición de las Conferencias Aranguren. El que ya sea la edición número veinticuatro da idea de la fuerza del pensamiento del profesor Aranguren. Como Rectora de la UNED tuve la suerte de conocerlo, no tanto como hubiera deseado pero sí lo suficiente como para admirar profundamente su magisterio. Hombre íntegro de 
pensamiento independiente despertaba en quienes lo trataban la inquietud intelectual que precede al auténtico conocimiento. Por ello, mi deuda de gratitud con el maestro Aranguren perdurará a través del tiempo.

Estas charlas estaban programadas para el otoño de 2015. Distintas vicisitudes hicieron que se suspendieran sine die, haciéndome pensar en su cancelación. Así que es de nuevo la insistencia de la profesora Roldán la que me sitúa ante Vds., más insegura que nunca, al tomar plena conciencia de hasta qué punto el tema elegido excede de mi ámbito profesional.

En descargo de mi osadía por esta incursión más allá de lo jurídicamente debido diré que, tras décadas consagrada al estudio y aplicación del Derecho, he llegado a la conclusión de que, para conseguir una sociedad más justa, el Derecho es imprescindible pero no suficiente. En efecto, por detallada que sea la regulación jurídica de la sociedad -y mi experiencia me hace dudar, y mucho, de que eso sea positivo-, una parte importante de la vida quedará siempre al margen. $\mathrm{Y}$ es en ese margen en donde los mandatos morales imponen unas normas de conducta que en buena medida condicionarán la salud cívica de una sociedad. Algo que resulta especialmente claro en momentos de crisis y muy especialmente de crisis económica cuando satisfacer las conquistas sociales de los menos favorecidos puede amenazar las ganancias de los más poderosos. Es entonces cuando la adopción de políticas, perfectamente legales, pueden hacer peligrar los derechos humanos de la mayoría, penosamente arrancados al poder durante siglos de lucha. Si tal fuera el caso, estaríamos ante una primera quiebra ética que habría que intentar prevenir pro futuro, reforzando si ello fuera posible las garantías y los controles jurídicos.

Por otra parte, el fenómeno de la corrupción es simultáneamente causa y consecuencia de las crisis. Sus efectos son además especialmente demoledores porque su misma existencia socaba la estructura ética de la sociedad. Por eso, resulta tan interesante explorar si la ética puede convertirse en un instrumento útil en la lucha contra la corrupción que la niega.

Así, afectación de los derechos humanos como consecuencia de la crisis y lucha contra la corrupción, se nos presentan como dos planos independientes entre sí, pero relacionados, ambos, con la vigencia, o falta de vigencia, de los mandatos éticos en la vida pública. Ahora bien, mi objetivo al abordar estas charlas sobre "la ética pública en tiempos de crisis" no es, no podía ser, el calificar desde el punto de vista ético las respuestas plurales que pueda recibir la pregunta de hasta qué punto la ética rige o, al menos, está presente en nuestra vida pública. Se trata, mucho más modestamente, de que hoy reflexionemos juntos, a la luz de los datos de que disponemos sobre cómo ha incidido la crisis sobre los derechos constitucionales en España, tanto en su configuración jurídica como en su disfrute efectivo. Para 
continuar, mañana, con el análisis del problema específico que plantea la corrupción y la posible colaboración de los Códigos éticos y de conducta en la lucha contra un fenómeno que refleja, como ningún otro, la miseria moral de sus protagonistas.

\section{LA INCIDENCIA DE LA CRISIS EN EL DISFRUTE DE LOS DERECHOS CONSTITUCIONALES EN ESPAÑA}

\section{Introducción}

Resulta evidente que cuando los medios son escasos en relación con necesidades que los desbordan la toma de decisiones sobre su asignación plantea necesariamente problemas éticos. Priorizar implica optar. Así es destacadamente en momentos de turbulencias económicas en que tal desfase puede llegar a plantear, como primera alternativa, si hay que atender a las personas que se ven arrastradas por la tormenta o ayudar para que se sostenga el edificio financiero sobre el que, en conjunto, se asientan las economías modernas. La elección va a venir determinada tanto por datos económicos como por el esquema de valores que prime en nuestra sociedad. Es decir, tanto por la economía como por la ética.

En principio, el dilema puede plantearse en términos muy directos: ¿personas o bancos? La respuesta, incluso para los que nos confesamos humanistas, no es fácil; y es que no lo es saber si el hombre puede sobrevivir en una sociedad avanzada del siglo XXI sin el concurso de determinadas estructuras, como las entidades financieras que, entre otras cosas, son el vehículo de incorporación a la vida cotidiana de las nuevas tecnologías (piénsese, por ej., en la domiciliación bancaria de nuestros recibos o en el uso de las tarjetas de crédito, sin olvidar que también son necesarias como intermediarias para que fluya el dinero, motor de la economía, y del desarrollo de la industria).

Pero los problemas éticos no se resuelven todos a este nivel. Solventado este primer escalón, el político ha de resolver todos los interrogantes a los que responde cualquier programa de gobierno. En él necesariamente habrá que priorizar entre colectivos y necesidades en respuesta a la gran cuestión de hacía donde han de dirigirse en primer lugar los fondos públicos. Parece evidente que para despejarla habrá que tener en cuenta una pluralidad de elementos. Por una parte, ¿hay algún colectivo que deba recibir una atención especial, p.ej. la infancia, la tercera edad o el que forman las personas con algún tipo de minusvalía? Por otra, ¿a qué necesidades subvenir de manera preferente: a la salud, a la educación, a la dependencia? Y junto a estas exigencias asistenciales, ¿qué lugar deben ocupar las políticas públicas de fomento?, ¿las que miran más directamente al futuro, como la investigación, por ejemplo, o las 
infraestructuras, indispensables para tener un mercado amplio? Las variables a introducir son tantas que sería ilusorio pensar que sólo hay una respuesta ética, siendo todas las demás censurables desde el punto de vista moral. Por el contrario, lo cierto es que caben distintas soluciones que, en atención a las concretas circunstancias de lugar y tiempo, resultarán más o menos adaptadas a los mandatos éticos de una sociedad determinada.

Con este planteamiento, en los minutos que siguen voy a ocuparme, como les decía, de la incidencia que la crisis ha tenido en el disfrute de los derechos constitucionales. Para hacerlo he dividido mi exposición en dos partes. En la primera me ocuparé del alcance y significado de la crisis. En la segunda, de cuáles son los derechos afectados por las políticas anti-crisis, para concluir con unas consideraciones finales.

\section{1. ¿QUÉ CRISIS?}

La incorporación del término crisis a nuestro lenguaje cotidiano se ha producido de forma tan natural que parecería innecesario que nos cuestionemos sobre su significado y alcance en la actual coyuntura. No lo creo así. Entiendo, por el contrario, que hay que recordar que, como señala la Real Academia de la Lengua, toda crisis implica la existencia de un "momento decisivo", sobre el que inciden factores de especial gravedad, y del que se pueden derivar consecuencias importantes susceptibles de ser, en principio, tanto positivas como negativas.

En el período que nos ocupa-que tentativamente podríamos concretar en los últimos ocho años- la primera manifestación de la crisis, es decir, de que estábamos en un momento decisivo con consecuencias imprevisibles, es de tipo económico. Sin embargo, no me detendré en su análisis: primero, porque sería incapaz de realizarlo con un mínimo rigor, y, segundo, porque estoy convencida de que la crisis afecta, como veremos más adelante, a otros muchos ámbitos, ajenos a la economía. Ahora bien, se impone reconocer que el detonante de la crisis del sistema ha sido una crisis económica que, en buena medida, responde a estímulos exteriores, determinantes en un mundo globalizado, pero que se han visto potenciados en España por la alta exposición financiera del sector inmobiliario. Como consecuencia, el PIB que en 2007 había crecido el 3,8\%, en 2008 experimentó un crecimiento de solo un 1,1\% (con una tasa negativa ya en el tercer trimestre), descendiendo hasta un negativo del 3,6\% en 2009. La ligera recuperación de 2010 y su posterior caída hacen que, en conjunto, a partir de 2007, el PIB español ofrezca un perfil en W, que desde finales de 2013 (aunque ese año el dato siguiera siendo de un negativo 1,7\% en términos interanuales), empieza a reflejar tasas positivas de crecimiento. Puede, por tanto, decirse que hemos sufrido una "gran recesión", de la que han 
sido víctimas especialmente las clases más vulnerables, entre las que se incluyen -y ésta es una nota peculiar de la actual crisis- las clases medias, y cuyas consecuencias perduran por encima de la incipiente recuperación económica.

Pero junto a esta crisis económica -la más dolorosa porque tiene consecuencias directas sobre la vida de los ciudadanos-, existen otras manifestaciones que apuntan a la existencia de una crisis global del sistema que afecta a las instituciones y a los postulados básicos de la democracia. Democracia pluralista sustentada sobre la limitación del poder y la garantía de los derechos que responde a la prefiguración constitucional de dos grandes pactos, el democrático y el social, "que caracterizan sustancialmente a los Estados constitucionales como Estados sociales y democráticos de Derecho".

Muy sintéticamente el pacto democrático se residenciaría en el respeto de la división de poderes -ejecutivo, legislativo y judicial-, del pluralismo político y de los derechos consagrados en la Constitución. Por su parte, el pacto social se reflejaría en el respeto básico de los factores que definen la economía de mercado, garantizando en contrapartida el disfrute de los derechos que configuran el Estado del bienestar.

Pues bien, este paradigma constitucional empieza a dar signos de debilidad cuando la práctica política se desvía paulatinamente del texto de la Constitución impidiendo que las instituciones puedan cumplir sus atribuciones con fidelidad a la misma. De este modo, en contraste con la realidad, el discurso constitucional explícito puede aparecer socialmente, como señala el profesor Balaguer $^{2}$, como construido en una lengua retórica o muerta. Y es que, la práctica política e institucional a que me refiero se desarrolla y justifica bajo una falaz "ideología de la crisis" que ampara el desdibujamiento de la división de poderes, la limitación del pluralismo político y la reducción drástica del componente social.

Los elementos fundamentales de la tramposa "ideología de la crisis" los ha sintetizado magistralmente el profesor Cámara y podrían resumirse como sigue: a) la economía, que es política e ideológicamente neutra (i!), está gravemente enferma y requiere de medidas radicales para su recuperación; b) la política y sus mecanismos democráticos deben supeditarse a ella y replegarse hasta que la economía se recupere; c) lo mismo ocurre con los derechos sociales y las políticas que los sirven, a la espera de recuperarlos plenamente cuando la crisis económica se supere; d) ello justifica, la reducción extrema del gasto público como

\footnotetext{
${ }^{1}$ G. Cámara Villar, “Crisis económica y Constitución. El caso de España”. Libro homenaje al profesor Carlos de Cabo. Texto generosamente cedido por el autor, p. 6 .

${ }^{2}$ Entre otras muchas obras del mismo autor, en F. Balaguer Callejón, "Crisis económica y crisis constitucional en Europa", Revista Española de Derecho Constitucional, núm. 98, mayo-agosto (2013)
} 
medio de alcanzar el equilibrio presupuestario; y, e) una última pieza esencial, hay que abaratar los costes empresariales, para lo cual es imprescindible introducir las reformas laborales que sean necesarias y que, dada su orientación, derivarán en la reducción de derechos y garantías de los trabajadores.

La debilidad de esta pseudo-ideología se encuentra, en mi opinión, en su misma base. Y es que, no acepto que exista una "ciencia" económica prescriptiva indiscutible, como avalan los planteamientos de muchos economistas de prestigio, y la constatación de que no todas las crisis económicas son homogéneas ni están generadas por el gasto social. Pero por falsa que sea una idea, si es seguida y mantenida por los poderes fácticos termina por convertirse en parte de la realidad y hemos de aceptar que, hoy por hoy, todo se produce como si los postulados de la "ideología de la crisis" fueran incontrovertibles. En consecuencia, se suceden las medidas que, apoyándose en ella, apuntalan su credibilidad, con la consiguiente pérdida de valor del principio democrático y la limitación del pluralismo.

Detengámonos por un momento en algunas de las manifestaciones en España del fenómeno que venimos denunciando.

1. En lugar destacado, porque afecta a la literalidad -y más allá- del texto constitucional, se sitúa la reforma del artículo 135 de la Constitución, de 27 de septiembre de $2011^{3}$. Una reforma -la segunda introducida en nuestra rígida Carta Magna- que nos vino exigida, aún antes de que se formalizara el Tratado de Estabilidad, Cooperación y Gobernanza en la Unión Económica y Monetaria, mediatamente por la voracidad de los mercados financieros, y, de manera inmediata, por algunos de nuestros socios en la UE.

A los efectos que aquí nos interesan en el nuevo artículo $135 \mathrm{CE}$ cabe distinguir dos planos: los límites constitucionales al déficit público, y, la prioridad del pago de la deuda, llamados, ambos, a repercutir en el disfrute de los derechos sociales, es decir, sobre el pacto social.

En el primer plano, el principio de estabilidad presupuestaria, que en sí mismo merece una acogida favorable como elemento de una adecuada política económica, ha recibido una rígida configuración normativa que "condiciona en exceso la capacidad para los poderes públicos de desarrollar políticas económicas anticíclicas y de mantenimiento de ciertos logros básicos y mínimos del Estado de bienestar que ya considerábamos prácticamente irreversibles"4. No obstante, la posibilidad ex núm. 4 del propio artículo, de que se superen los límites de déficit estructural y de volumen de deuda pública, consagrada ciertamente con carácter excepcional y en términos muy restrictivos, permi-

\footnotetext{
${ }^{3}$ Publicada en el BOE el mismo día de su entrada en vigor.

${ }^{4}$ G. Cámara Villar, ob.cit., pg. 9
} 
ten entender que la introducción de este principio no ha destruido de manera estructural el pacto social subyacente a nuestra Constitución.

Cosa distinta es que, en la práctica, el equilibrio presupuestario a toda costa se utilice como coartada para recortar políticas sociales que son la encarnación del Estado social. En tal supuesto el deseable equilibrio presupuestario se alza como el gran argumento político-ideológico que permite el desmantelamiento del Estado del bienestar, poniendo en riesgo el goce efectivo de los derechos constitucionales.

Más negativo resulta aún, en mi opinión, el segundo plano señalado, es decir, el de la prioridad absoluta de la devolución de la deuda pública. Y es que, en este punto el tenor del precepto -el art. 135.3, segundo párrafo- no admite interpretaciones cuando establece que "los créditos para satisfacer los intereses y el capital de la deuda pública de las Administraciones se entenderán siempre incluidos en el estado de gastos de sus presupuestos y su pago gozará de prioridad absoluta" Ello implica que la asignación equitativa del gasto público se encuentra condicionada por el previo pago de la deuda; de este modo, el gran pacto social subyacente a la Constitución por el cual el respeto de las condiciones del mercado se ve contrapesado por las necesarias prestaciones sociales, se ve alterado puesto que las prestaciones sociales quedan subordinadas a las exigencias del mercado. Y ello, al margen de las consecuencias que sobre el primitivo pacto constitucional implícito tiene la propia evolución del capitalismo que ha pasado de productivo a especulativo, con la consiguiente dificultad para "contabilizar beneficios".

Para terminar con este punto, señalamos, por último que, además, por esta vía se produce también una primera consecuencia negativa para el principio democrático, desde el momento en que un concreto entendimiento de la economía termina imponiéndose a las opciones políticas que, subordinadas a las exigencias económicas, de algún modo se vuelven irrelevantes, con el consiguiente atentado al pluralismo.

2. Una segunda consecuencia de los planeamientos de la "ideología de la crisis", afecta sobre todo al gran pacto democrático sobre el que se asienta la Constitución, al incidir negativamente sobre la competencia legislativa de las Cortes. Se trata tanto de la legislación a través de "leyes ómnibus" de contenido heterogéneo y de la inclusión de enmiendas en el Senado -en la fase final del proceso legislativo- sin relación con el objeto del proyecto legal debatido, como del recurso habitual a la legislación mediante Decretos Leyes. Sobre todos estos extremos la doctrina de nuestro Tribunal Constitucional es clara aunque su aplicación al caso concreto resulte fluctuante.

La primera aproximación del Tribunal Constitucional (TC) a las leyes de contenido plural la realizaría en relación con las Leyes de Presupuestos Generales del Estado, fijando una doctrina limitativa de su contenido even- 
tual. Entendió el Tribunal que la inclusión en las mismas de disposiciones ajenas a la disciplina presupuestaria constituía una "restricción ilegítima" de las competencias del poder legislativo (STC 76/1992, de 14 de mayo, FJ 4), por lo que su constitucionalidad quedaba supeditada a su vinculación con previsiones de ingresos y autorizaciones de gasto, incluidas en los Presupuestos proyectados (STC 63/1986, de 21 de mayo, FJ 12). Como se deduce del razonamiento del TC, la razón de ser de la restricción al contenido eventual de las Leyes de Presupuestos reside en que su tramitación condicionada por la necesidad de su aprobación en un período determinado, se traduce en el acortamiento de plazos y, por tanto, del tiempo de estudio y enmienda.

Saliendo al paso de estas objeciones los sucesivos Gobiernos -al margen de su color político- han recurrido a las Leyes de medidas fiscales, administrativas y de orden social (también denominadas "leyes de acompañamiento"), que aunque aprobadas coetáneamente con las Leyes de Presupuestos siguen los preceptivos trámites parlamentarios. Se trata de leyes que constituyen un auténtico popurrí legislativo. Sobre su constitucionalidad se pronunció el TC en su Sentencia 136/2011, de 13 de septiembre -de la que fui ponente-, que se refería a la Ley 50/1998, de 30 de diciembre por la se modificaron ; 76 leyes, 7 decretos legislativos y 6 decretos leyes! Las cifras son apabullantes y sugieren una primera objeción de constitucionalidad referida a la seguridad jurídica (art. 9.3 CE). No obstante, el Tribunal terminará avalando la utilización de este tipo de leyes al constatar que el dogma de la homogeneidad de las leyes no existe en la Constitución Española, pese a señalar que tal forma de proceder "es expresión de una deficiente técnica legislativa" (FJ 3).

Sin duda el juicio podía haber sido mucho más severo, pero el Tribunal optó por la auto-contención prudente, en ausencia de norma constitucional que limite taxativamente las opciones del Gobierno en la elaboración de los proyectos de leyes que somete a las Cortes. Y ello pese a ser consciente de las dificultades añadidas que tal modo de proceder supone para que los miembros de las Cámaras desarrollen correctamente su función.

Por el contrario, precisamente por afectar a la esencia de la función representativa de los parlamentarios, el TC en la Sentencia 119/2011, revisando su jurisprudencia previa ${ }^{5}$, se ha mostrado mucho más exigente sobre la posibilidad de calificar como enmiendas, iniciativas cuyo contenido resulta totalmente ajeno al objeto del proyecto de ley debatido. En este sentido, la citada Sentencia señala que violenta la posición institucional del Senado

\footnotetext{
${ }^{5}$ Así lo destaca en el FJ 6 de la STC 119/2011, de 5 de julio.
} 
calificar como enmiendas lo que supone una iniciativa legislativa nueva ${ }^{6}$, razonando que "el derecho de enmienda que pertenece a los parlamentarios... no es un mero derecho reglamentario sino un auténtico contenido central de su (de los Senadores) derecho de partición del art. 23.2 CE" (FJ 9). De este modo, "la calificación como enmiendas de lo que, por carecer de relación alguna de homogeneidad con el texto enmendado, suponía una iniciativa legislativa nueva, impidió a los recurrentes utilizar los mecanismos previstos en el art. 90.2 CE, que constituyen la esencia de su función representativa como Senadores" (FJ 9).

Pese a todo, aunque con las restricciones deducidas por el TC del texto constitucional, se ha ido consolidando una práctica legislativa de dudosa calidad democrática por la utilización expansiva de sus competencias de iniciativa por parte del Poder Ejecutivo. Con ser ello grave, no es ésta la única manifestación del debilitamiento del pacto democrático que plasma nuestra Constitución. Junto a ella, como señalaba, otro factor va a contribuir a su deterioro. Me refiero al uso abusivo de los Decretos-leyes, un instrumento legislativo puesto a disposición del Gobierno por la Constitución en determinadas condiciones recogidas en su artículo 86 . Condiciones que se resumen, por una parte, en el presupuesto habilitante de que la situación sea de "extraordinaria y urgente necesidad"; por otra, en la condición de que se respeten los ámbitos materialmente vedados a los decretos-leyes entre los que se encuentra la prohibición de que con ellos se afecten los derechos, deberes y libertades de los ciudadanos.

En principio, el respeto de los límites materiales de los Decretos-leyes resulta fácilmente discernible en el caso concreto. Así, por ejemplo, en un supuesto en que se planteaba si un Decreto-ley había invadido el principio de reserva de ley del artículo $31.3 \mathrm{CE}$ y del deber de contribuir de su apartado 1, el Tribunal señaló que hay que mantener una posición equilibrada "que evite las concepciones extremas, de modo que 'la cláusula restrictiva del art. 86.1 de la Constitución ("no podrán afectar") debe ser entendida de modo tal que ni reduzca a la nada el Decreto-ley, que es un instrumento normativo previsto en la Constitución... ni permita que por Decreto-ley se regule el régimen general de los derechos, deberes y libertades del título I' (SSTC 111/1983, de 2 de diciembre, FJ 8; 60/1986, de 20 de mayo, FJ 4; 182/2004, de 30 de junio, FJ 7). Posición que nos llevado a concluir en aquel caso que el Decreto-ley 'no

${ }^{6}$ Se trataba de la Ley Orgánica complementaria de la Ley de arbitraje. Las enmiendas introducidas en el Senado, por su parte, añadían los arts. 506 bis, 521 bis y 576 bis al Código Penal, tipificando el delito de convocatoria ilegal de elecciones o de referéndum, así como el allegar fondos públicos para asociaciones ilegales o partidos políticos disueltos o suspendidos. 
puede alterar ni el régimen general ni los elementos esenciales del deber de contribuir...' (por todas, STC 108/2004, de 30 de junio, FJ 7)"”.

Más complejo resulta precisar cuándo concurre el presupuesto habilitante de la extraordinaria y urgente necesidad, tanto porque estamos ante un concepto de naturaleza jurídica indeterminada, como porque depende de un juicio de oportunidad que corre el riesgo de convertirse en el único criterio de validez. Por ello no puede extrañar que sea el condicionante que ha merecido mayor atención por parte de la jurisprudencia constitucional. El punto de partida es claro, como ha señalado el propio TC, al afirmar que hay que "reconocer el peso que en la apreciación de la extraordinaria y urgente necesidad ha de concederse al juicio puramente político de los órganos a los que incumbe la dirección del Estado". No obstante lo cual también ha insistido en que "la necesaria conexión entre la facultad legislativa excepcional y la existencia del presupuesto habilitante conduce a que el concepto de extraordinaria y urgente necesidad que se contiene en la Constitución no sea, en modo alguno, una cláusula o expresión vacía de significado dentro de la cual el lógico margen de apreciación política del Gobierno se mueva libremente sin restricción alguna, sino, por el contrario, la constatación de un límite jurídico a la actuación mediante decretos-leyes". Por tanto, "el Tribunal Constitucional podrá, en supuestos de uso abusivo o arbitrario, rechazar la definición que los órganos políticos hagan de una situación determinada y, en consecuencia, declarar la inconstitucionalidad de un Decreto-ley por inexistencia del presupuesto habilitante por invasión de las facultades reservadas a las Cortes Generales por la Constitución"».

Riesgo de abuso que, como prueba la práctica, tiende a exacerbarse en momentos de crisis económica en que superarla se convierte en único criterio de validez y última legitimación de cualquier medida que se adopte. Así ha ocurrido de hecho con el frecuente recurso a los Decretos-leyes a lo largo de la última legislatura, del que es buena prueba el Real Decreto-ley 8/2014, de 4 de julio, que, podría calificarse de Decreto-ley ómnibus -a imagen y semejanza de las leyes ómnibus- y en el que se abarca "desde la legislación laboral y tributaria hasta el cine, desde la energía, las minas o los hidrocarburos hasta la conmemoración de la primera exposición de Picasso, desde la carrera militar hasta los puertos y aeropuertos, desde los horarios comerciales hasta el Registro Civil. Y este rasgo no solo afecta al contenido dispositivo, sino también a las variopintas razones esgrimidas para justificar la concurrencia del presupuesto habilitante, y que en buena parte resultan retóricas, hueras, discutibles

${ }^{7}$ STC 189/2005, de 7 de julio, FJ 7.

${ }^{8}$ STC 189/2005, de 7 de julio, FJ 3, con cita de las SSTC 11/2002, de 17 de enero, FJ 4; y 137/2003, de 3 de julio, FJ 3. 
o, más sencillamente, inexistentes", como señala el Voto Particular anexo a la STC 199/2015, de 24 de septiembre'. En su Sentencia, el TC entra en la valoración sectorial de los grupos de medidas incorporadas en el Real Decreto-ley y declara inconstitucionales algunas de ellas, por falta del presupuesto habilitante, sin realizar la reflexión de orden general sobre los límites constitucionales a la legislación de urgencia, que reclama el citado Voto Particular.

No puedo ocultar que comparto la opinión de la minoría de Magistrados que lo suscriben. En efecto, por acertado que resulte el juicio técnico sobre la adecuación individualizada de las distintas disposiciones adoptadas a los límites constitucionales de los Decretos-leyes, con él no se puede obviar la consideración de las alteraciones que sobre el equilibrio de poderes consagrado en la Constitución proyecta una norma que modifica una parte sustancial del ordenamiento jurídico sin la intervención previa de los representantes democráticamente elegidos por el pueblo. Una situación que genéricamente busca cobertura en una desastrosa realidad económica que hay que solventar con urgencia y a cualquier precio; es decir, por razones inspiradas en la ideología de la crisis tan fielmente reflejada en el apartado I del preámbulo del Real Decreto-ley sujeto a escrutinio constitucional. Pues bien, como dijera el TC al ocuparse de los límites constitucionales al derecho de enmienda en las Cortes Generales, "desatender los límites constitucionales bajo el paraguas de la urgencia normativa no deja de ser una lesión constitucional por mucho que pueda parecer conveniente coyunturalmente"

Sin duda, éstos son argumentos difícilmente asumibles por quiénes sufren la mordida del hambre y el desamparo, y que pueden sentir la tentación de apostar por una legislación emanada del ejecutivo que tiene carácter inmediato al eludir "engorrosos" trámites parlamentarios. Por otra parte, se puede argumentar que cuando existe mayoría absoluta en las Cortes el resultado del debate parlamentario se conoce de antemano porque siempre será acorde con la voluntad gubernamental; no obstante, el debate permite la manifestación de las distintas posiciones representadas por las diferentes fuerzas políticas, haciendo posible además que los argumentos de las minorías terminen influyendo sobre las tesis de la mayoría parlamentaria que apoya al Gobierno, aunque sólo sea por evitar la imagen de aislamiento. Pues bien, al hurtar ese debate, nos alejamos progresivamente y cada vez más del Estado de Derecho ideal que nuestra Constitución aspiraba a consolidar para que asegurara "el imperio de la ley como expresión de la voluntad popular".

${ }^{9}$ El Voto Particular está suscrito por la Magistrada doña Adela Asua Batarrita y los Magistrados don Fernando Valdés Dal-Ré y don Juan Antonio Xiol Rios.

${ }^{10}$ STC 119/2011, citada, FJ 7. 
De este modo, entre la indiferencia de muchos y la pasividad de otros, las voces de la oposición política no logran evitar el progresivo deterioro del poder legislativo, con la consiguiente pérdida de calidad democrática de todo el sistema. El gran pacto democrático sobre el que se construyó nuestra Constitución empieza así a mostrar fisuras que amenazan nuestra convivencia y que pueden pasar, de ser una consecuencia de la crisis, a convertirse en causa principal de su agravamiento.

\section{2. ¿QUÉ DERECHOS?}

La profundidad y el carácter multiforme de la crisis hacen que su incidencia sobre los derechos constitucionales sea potencialmente total. Si sus primeras manifestaciones económicas repercutieron básicamente sobre los derechos sociales, la prolongación de la crisis y su reflejo a nivel institucional han derivado en atentados contra derechos civiles y políticos que, en principio, parecían a resguardo de recesiones coyunturales. Así, la conclusión que se impone es que en este epígrafe nos referimos a "todos" los derechos, y habría que añadir, que con independencia de su veste jurídica, es decir, al margen de que se consagren en la Constitución como derechos fundamentales, derechos y deberes de los ciudadanos, o como principios rectores que han de informar "la legislación positiva, la práctica judicial y la actuación de los poderes públicos" (art. 53.3 CE). Y es que, todos ellos, al margen de la literalidad de su enunciado e incluso de las medidas destinadas a su defensa, constituyen el acervo de derechos que constitucionalmente corresponden a los españoles.

Tal enfoque se justifica por la propia Constitución, que en su artículo 1 proclama que España se constituye en un Estado social y democrático de Derecho, y que se dota además de instrumentos esenciales para garantizarlo. De hecho, la Constitución junto a las declaraciones solemnes (ya en su Preámbulo cuando habla de "un orden económico y social justo"), incluye mandatos a los poderes públicos, como el contenido en el artículo 9.2 de "promover las condiciones para que la libertad y la igualdad del individuo y de los grupos en que se integra sean reales y efectivas".

Pero la Constitución va más allá cuando en su artículo 31.2 introduce un principio de justicia en la distribución del gasto público, al disponer que éste "realizará una asignación equitativa de los recursos públicos, y su programación y ejecución responderán a los criterios de eficiencia y economía". Producto de una enmienda del profesor Fuentes Quintana" ${ }^{11}$, como ha señalado

${ }^{11}$ Enmienda presentada en la Comisión Constitucional del Senado (BOC de 6 de octubre de 1978). 
Pascual Sala, que fuera Presidente del Tribunal Constitucional, "[1]a introducción de este precepto constitucional constituyó una decidida superación de las posiciones doctrinales que habían considerado siempre las decisiones de gasto público como materia puramente política" ${ }^{12}$. En efecto, prescribir que la asignación de recursos se haga de manera equitativa refuerza el contenido normativo de la Constitución ya que, a la hora de establecer que sea "equitativo", habrán de tenerse en cuenta los derechos de los ciudadanos. Por esta vía puede sostenerse que la Constitución contiene mandatos directos al Poder Ejecutivo (al elaborar los Presupuestos) y al Legislativo (al aprobarlos) en orden a satisfacer los derechos prestacionales y sociales de los ciudadanos (a la educación, al trabajo y a la negociación colectiva, por ejemplo), así como a dar cumplimiento a los principios rectores (entre otros, protección de la familia, progreso social y económico; régimen público de Seguridad Social; protección de la salud; fomento de la cultura; medio ambiente adecuado; vivienda digna y adecuada; pensiones adecuadas y periódicamente actualizadas, entre otros).

Precisamente estos mandatos, que constituyen la esencia del Estado social, son como señalaba la contrapartida de la constitucionalización de la economía de mercado, integrando el gran pacto social al que me vengo refiriendo. Pues bien, resulta claro que la nueva redacción del artículo 135.3 CE, estableciendo que los créditos e intereses de la deuda pública se entenderán siempre incluidos en el estado de gastos de los presupuestos, y que gozarán "de prioridad absoluta", gravita sobre este pacto, que resulta además amenazado de modo directo por políticas restrictivas del gasto social y que se potencian negativamente, sobre todo con la reforma del mercado laboral.

Entre los objetivos de esta charla no entra, ni puede entrar, el análisis de todas las medidas que, a lo largo de una crisis que se prolonga ya dos legislaturas, han modificado el Derecho del trabajo y han reducido las partidas presupuestarias destinadas a servicios públicos que se corresponden con derechos prestacionales de los ciudadanos. Las razones son tanto de competencia -no soy ni laboralista ni economista-, como de prudencia temporal ya que la exposición y análisis de estas medidas desbordan con mucho los límites de una conferencia $^{13}$. Me limitaré, por tanto, a ofrecer algunos datos que, a modo de

${ }^{12}$ Sala Sánchez, P., Discurso de investidura como Doctor "Honoris causa" por la Universidad de Valencia. Valencia, 26 de mayo de 2014, pág. 85

${ }^{13}$ Una exposición completa, aunque no exhaustiva, puede verse en Julia Lladós Vila y Teresa Freixas, The impact of the crisis on fundamental rights across Member States of the EU. Country Report on Spain, de 30 de junio de 2014. (http://www.europarl.europa.eu/studies). Documento solicitado por el "Committee on civil liberties, justice and home affairs" del Parlamento Europeo. Los datos que utilizo en esta exposición proceden en gran medida de esta publicación. 
brochazos, pueden ayudar a dibujar el panorama que tenemos cuando empezamos a dar por superada la crisis económica.

Por lo que se refiere al mercado del trabajo, el abaratamiento de los despidos y la facilitación de los despidos colectivos han roto el dualismo anterior a la crisis entre empleos fijos y empleos temporales, en favor claramente de los segundos con la consecuencia de una mayor inseguridad en el trabajo. Al mismo tiempo ha aumentado muy significativamente, tanto el trabajo temporal involuntario -que pasa del $87.2 \%$ en 2008 a $91.7 \%$ en $2013-$, como el trabajo a tiempo parcial involuntario, con cifras que en este caso, en el mismo periodo de tiempo, casi se duplican (de $36.0 \%$ a $63.3 \%$ ). Pues bien, con un mercado del trabajo especialmente "volátil" no es de extrañar que los sueldos hayan bajado como promedio un $1.8 \%$ anual desde 2008 , en una situación en la que los sindicatos pierden poder y las relaciones laborales se judicializan de manera creciente. En este concreto ámbito, las medidas empiezan con el Real Decreto-ley 10/2010, de 16 de junio y la Ley 35/2010, de 17 de septiembre, para continuar con el Real Decreto-ley 3/2012, de 10 de febrero y la Ley 3/2012, de 6 de julio.

La consecuencia es una población trabajadora -de clase baja y mediaempobrecida, y es sobre este telón de fondo sobre el que se van a proyectar los recortes presupuestarios a las políticas sociales. En mayor o menor medida todas se han visto afectadas. No obstante, la necesidad de seleccionar se impone, por lo que en las consideraciones que siguen me limitaré a hablar de educación y sanidad, las dos políticas que afectan a mayores capas de población. Con esta restricción soy consciente de que al hacerlo dejo al margen de esta reflexión políticas tan decisivas en una sociedad avanzada como la dependencia o la vivienda, que requieren, respectivamente, de mayores aportaciones económicas, en el caso de la dependencia, y de la adopción de medidas legislativas valientes, en cuanto a la vivienda, que den una regulación más equilibrada al régimen hipotecario y que aborden con decisión la regulación de la insolvencia personal. Pero la prudencia "temporal" obliga.

En cuanto a la educación pública, a las medidas que han afectado al profesorado como trabajadores públicos -reducción de salarios o incremento de las horas de trabajo-, se han sumado otras específicas del sector -así el aumento de la ratio profesor-alumno-. Por otra parte, la reducción de las restantes partidas presupuestarias destinadas a educación (de un 40\%) ha repercutido en un alarmante descenso de las becas de estudio o de su cuantía, de las cantidades dedicadas a financiar los libros escolares (hasta el $45 \%$ menos) y de las asignaciones para los comedores escolares (entre el 30 y el $50 \%$ ). 
Cifras que muestran que las medidas de austeridad están "castigando" de manera especial a la infancia, al afectar tanto a la igualdad en el sistema educativo como a su calidad, influyendo así de manera decisiva en la formación académica. Por lo demás, la creciente pobreza infantil (que alcanzaba ya el $30.6 \%$ en 2011; es decir un 10\% más que en 2008) puede llegar a afectar negativamente al desarrollo económico y social del país a largo término ${ }^{14}$. En otro orden de consideraciones, no hay que olvidar las amplias competencias que tienen las Comunidades Autónomas en materia educativa, lo que hace que los datos anteriores tengan solo un valor relativo en cada una de las diecisiete Comunidades Autónomas, lo que ciertamente no ayuda a evaluar exactamente la situación.

La misma observación ha de hacerse en relación con la sanidad, aunque una vez más, dado que al Estado le corresponde el establecimiento de las bases y de la coordinación general de la sanidad, pueden deducirse rasgos generales aplicables al conjunto del sistema sanitario. En materia sanitaria el Real Decreto-ley 16/2012, de 20 de abril (en vigor, el 1 de julio) traza una línea divisoria. Antes de la reforma, España presentaba un sistema de acceso universal y libre a la sanidad, que ha sido sustituido por un sistema basado en el "employment status", es decir, condicionado al pago de contribuciones al sistema de Seguridad Social. Ello ha traído, como consecuencia, la exclusión de los beneficios generales de sectores de la población, entre los que destacan cuantitativamente los inmigrantes no documentados, es decir, los extranjeros sin permisos de residencia.

A lo anterior hay que sumar la reducción del gasto sanitario que se ha concentrado, sobre todo, en el farmacéutico con la introducción del co-pago de medicamentos. No obstante, la política de ahorro se ha traducido también en la no reposición de las vacantes del personal médico y de enfermería, así como con la supresión de camas hospitalarias. En términos globales, se estima que entre 2010 y 2014 la inversión en sanidad por persona ha disminuido en torno a 150 euros anuales ${ }^{15}$.

Pese a su carácter fragmentario estos datos deberían alertarnos sobre las consecuencias de la austeridad como única receta en tiempo de crisis. Una apreciación que comparte el Alto Comisionado de las Naciones Unidas para los Derechos Humanos cuando señala que las medidas de austeridad plantean importantes dudas en cuanto a la protección de los derechos económicos, sociales y culturales, además de no contribuir necesariamente a la recuperación económica ${ }^{16}$.

${ }^{14}$ The impact of the crisis..., ob. cit., pg. 30.

${ }^{15}$ The impact of the crisis..., ob.cit. pg. 37

${ }^{16}$ OHCHR, Report of the United nations High Commissioner for the Human Rights: Austerity measures and economic, social and cultural rights, 2013 www.ohchrorg/Documents/Issues/Development/RightsCrisis/E-2013-82 en pdf 
Por mi parte voy aún más allá. La adopción de medidas que progresivamente han ido afectando a más sectores sociales ha terminado por anestesiar a una gran parte de la población que ante los primeros recortes reaccionaron con manifestaciones masivas (las llamadas mareas, verdes o blancas) que, sin embargo, fueron perdiendo fuelle ante un poder ejecutivo inamovible.

Así, en medio del desánimo ciudadano y con una fuerte oposición de amplios sectores profesionales, una nueva medida que afecta directamente al derecho de acceso a la justicia (art. 24.1 CE) va a reintroducir las tasas judiciales con carácter general, salvo en la jurisdicción penal ${ }^{17}$. La medida en cuestión resulta especialmente llamativa porque afecta a un derecho político y porque su adopción, al menos como objetivo principal, no puede justificarse por una finalidad recaudatoria. Y, aunque pueda explicarse desde la búsqueda de una racionalización de la Administración de Justicia, lo cierto es que, sea éste un efecto querido o no, también va a incrementar el desamparo, con el consiguiente descontento, de una parte de la población al disuadirla de buscar la tutela judicial efectiva que, como un derecho, proclama la Constitución.

Por último, en este rápido recorrido de las consecuencias sobre los derechos constitucionales de las crisis del sistema, se impone una referencia a la Ley Orgánica 4/2015 de 30 de marzo (en vigor desde el 1 de julio de 2015), de protección de la seguridad ciudadana, popularmente conocida como "Ley mordaza" que, al establecer los términos de un nuevo equilibrio entre seguridad y libertad, procede a una configuración restrictiva de los derechos de expresión y reunión, en que la balanza se inclina decididamente del lado de la seguridad. Por el momento, el texto legal cierra así un debate presente en todas las sociedades occidentales, aunque no creo que el cierre sea definitivo. De hecho algunas de las disposiciones de la Ley han sido recurridas ante el Tribunal Constitucional por la mayoría de los Grupos Parlamentarios de la oposición ${ }^{18}$. Pues bien, sin pretender avanzar un juicio que solo corresponde a nuestro Alto Tribunal, lo que sí puede aventurarse es que una de las razones de ser de la norma, se encuentra en la necesidad de hacer frente a protestas ciudadanas dirigidas, básicamente, contra las políticas de austeridad. Por tanto, puede afirmarse que una cierta forma liberal de configurar las libertades de expresión y reunión ha sido también víctima de la crisis.

${ }^{17}$ Suprimidas en 1986, la Ley 53/2002, de 30 de diciembre, las reintrodujo en los órdenes civil y contencioso-administrativo respecto de las sociedades con ingresos altos. Más adelante la Ley 10/2012, de 20 de noviembre, las extiende a las personas físicas en las jurisdicciones civil, administrativa y laboral. Por último el Real Decreto-ley 3/2013, de 22 de febrero, ha reducido su cuantía.

${ }^{18}$ El recurso, suscrito por Diputados pertenecientes a los Grupos Parlamentarios de PSOE, Izquierda Plural, UPyD, Compromis-equo, Coalición Canaria y Geroa Bai, se presentó en el TC el 21 de mayo de 2015. 


\section{A MODO DE CONCLUSIÓN}

Tras haberle tomado el pulso al estado en que se encuentran los pactos implícitos sobre los que construimos en 1978 nuestro sistema constitucional creo que se puede concluir que, aunque afectados -incluso, seriamente afectados-, siguen respondiendo al equilibrio que ha sustentado más de treinta años de convivencia democrática de los españoles. Por eso, entiendo que ética y políticamente estamos obligados a intentar restañar las quiebras que han sufrido en los años consagrados a salir de una recesión económica que ha terminado por conducirnos a una crisis sistémica.

Y a partir de aquí mi intervención deja de apoyarse en datos objetivos para convertirse en una reflexión personal y apasionada, sin más valor que el que Vds. quieran darle.

Ante todo, se impone superar la "ideología de la crisis" que se ha traducido en los últimos años en la adopción de recortes en las partidas presupuestarias destinadas a sostener las políticas públicas en sectores especialmente sensibles como la dependencia, la educación y la sanidad. Su invocación, hasta el punto de que puede hablarse de "la crisis como política"19, como hemos visto, ha trascendido, además, de los "recortes" acordados en nombre de la austeridad, a la ordenación del mercado del trabajo y de otros sectores desde el energético a la Administración de justicia. Por otra parte, es la misma ideología que ha justificado la legislación de urgencia, mediante reales decretos, orillando el papel central que en un sistema parlamentario corresponde al Parlamento, reducido en buena medida a mera caja de resonancia de las políticas gubernamentales.

En cuanto a las medidas concretas que pueden adoptarse considero que el artículo $135 \mathrm{CE}$ modificado bajo la presión de los mercados, debería volver a ser reformado para desactivar su potencial amenaza al pacto social, eliminando la frase que garantiza que el pago de la deuda pública "gozará de prioridad absoluta". De acuerdo, pues, con que se mantenga la obligación del pago, incluso a nivel constitucional, pero eliminemos una frase que introduce una rigidez absoluta en un compromiso que debería dejar a la política un margen de acción en supuestos de emergencia social.

Por otra parte, hay que blindar con los mecanismos que resulten adecuados (aunque exijan igualmente de una reforma constitucional) algunos de los derechos sociales que hoy figuran en nuestra Constitución como principios rectores, perfilando las obligaciones de las Administraciones públicas en relación con aquellos que difícilmente admitirían su conversión en Derechos fundamentales

${ }^{19}$ La expresión la tomo de José Manuel PUREZA, cuyo libro Linhas Vermelhas lleva como subtítulo "crítica da crise-como-política". Bertrand Editora. Lisboa, 2015. 
-pienso, concretamente, en el Derecho a la vivienda. Todo ello sin olvidar que el derecho al trabajo es la pre-condición de un Estado social que, al mismo tiempo, resulte competitivo en los mercados. Lograr un equilibrio que recupere los derechos laborales sin afectar a la competitividad es un desafío ineludible y urgente.

Por último, en cuanto a la crisis institucional pocas dudas caben de que la salida pasa por fortalecer la división de poderes, de tal forma que los poderes legislativo y judicial gocen de la independencia que necesitan para desarrollar sus cometidos; en efecto, hay que insistir en la idea de que la separación de los poderes no es precisamente un capricho académico sino una exigencia práctica de cualquier sistema democrático.

Para concluir permítanme que vuelva al principio de mi intervención cuando me refería a la dificultad de calificar éticamente conductas o políticas: es cierto que tal vez sea difícil saber si un determinado comportamiento es ético; lo que sin duda no es tan difícil es saber cuándo no lo es. A cada uno de Vds. le corresponde decidir que comportamientos entran en una u otra categoría, y ha de hacerlo aplicando sus propios principios porque, en medio de todas las dudas que les he expuesto de lo que sí estoy convencida, es de que no debemos permitir que nadie sustituya nuestro juicio moral.

\section{II. ÉTICA PÚBLICA Y LUCHA CONTRA LA CORRUPCIÓN}

\section{Introducción}

La corrupción y las distintas vías para combatirla es un tema que ocupa y preocupa, con toda razón, a la ciudadanía. El concepto de corrupción es claro y no parece requerir de mayores explicaciones; no obstante, sí que resulta conveniente precisar la noción de "corrupción política" en la que se centrarán las reflexiones que siguen. En términos generales, la corrupción política implica la utilización del poder para fines distintos de la correcta gestión de lo público; dicho en otros términos, supone el abuso de un puesto público para obtener una ganancia privada, personal. A su vez, desde posiciones privadas de poder (muy señaladamente económicas) se puede incitar o favorecer la corrupción cuando se utiliza para conseguir de los poderes públicos privilegios a cambio de algún tipo de contraprestación, que directa o indirectamente acabará siendo económica. Por tanto, lo característico de la corrupción política no es sólo el desvío de fondos públicos a las manos privadas de sus administradores naturales (los cargos públicos), sino también la utilización del poder político para obtener beneficios económicos, normalmente de origen privado. 
Frente a tales comportamientos se alzan los valores éticos que deben guiar las conductas humanas en la sociedad, cuya misma estabilidad resulta en entredicho por la corrupción. Y es que, cuando alcanza cotas muy altas, inasumibles por la ciudadanía -y aquí el grado de tolerancia social va a depender tanto de pautas culturales como del bienestar o "malestar" económico-, la corrupción llega a atentar contra el sistema democrático.

Ésta es, en mi opinión, la situación en que se encuentra España en el primer cuarto del siglo XXI, en el que parece claro que los casos de corrupción que han salido a la luz resultan objetivamente intolerables en un Estado de Derecho, siendo también claro que un amplio sector de la población no parece subjetivamente dispuesto a tolerarlos en un momento en que la crisis afecta sustancialmente al disfrute de sus derechos. En efecto, en la actual coyuntura la corrupción afecta a instituciones básicas del Estado en las que plasman los distintos poderes, extendiéndose también a partidos políticos, sindicatos y organizaciones empresariales, lo que se traduce en la desafección de la ciudadanía hacía sus políticos. Una desafección que, como señalaba, puede hacer peligrar el sistema democrático. Es lo que ocurre cuando el pueblo en el que reside la soberanía, que ejercita a través de las urnas, percibe a la clase política como una oligarquía que ostenta el poder en su propio beneficio. De hecho, algunos eslóganes - como el repetido "que no nos representan"- en que se traduce la frustración de tantos por el comportamiento de tan pocos, parecen abocarnos a la búsqueda de "salvadores", ajenos por definición al juego democrático.

En este sentido entiendo que puede afirmarse que democracia y corrupción son incompatibles, desde el momento en que los ciudadanos toman conciencia de que el sistema se encuentra corroído por la injerencia de intereses privados en la gestión de lo público, de lo común. Por tanto, para los demócratas, para los que creemos con Winston Churchill que "la democracia es el peor sistema de gobierno, a excepción de todos los demás", la lucha contra la corrupción es una prioridad para alcanzar una democracia de mejor calidad.

En la exposición que sigue voy a ocuparme, en primer lugar, de los distintos instrumentos de que disponemos en la lucha contra la corrupción, para pasar, en segundo término, a exponer la experiencia ciertamente novedosa que está desarrollando desde hace tres años el Gobierno vasco. Finalmente, concluiré con algunas de las reflexiones teñidas de subjetivismo que el tema me sugiere.

\section{INSTRUMENTOS EN LA LUCHA CONTRA LA CORRUPCIÓN}

Aun asumiendo la dificultad de erradicar en todos los grados (desde la corrupción que podríamos denominar "blanda" hasta la gran corrupción que solo 
está al alcance de los más poderosos) y a todos los niveles (desde la del ciudadano de a pie a la del Jefe del Estado), la lucha contra la corrupción resulta un imperativo si queremos preservar el Estado de Derecho. Una lucha que ha de desarrollarse en distintos frentes, recurriendo a mecanismos diversos.

El primero, por su contundencia y por su condición de ultima ratio lo constituye la sanción penal que, aunque resulte sorprendente, es poco eficaz y de dudoso valor ejemplarizante. Poco eficaz, ya que sólo puede producirse ex post, una vez que el acto de corrupción se ha perfeccionado. Por lo demás, su dudosa ejemplaridad se deriva de que en un sistema penal garantista -que soporta mejor un culpable fuera de la cárcel que un inocente dentro-, la duración de los procesos, en manos de abogados expertos, puede hacer que el ciudadano ponga en cuestión todo el sistema. Y es que, para que la sanción penal resulte disuasoria ha de poder relacionarse directamente con la conducta sancionada. Ello implica que sea pronta y que se perciba como inevitable; por otra parte, la cuantía/duración de la pena "no puede compensar" puede ser que en el cálculo de penalización/ganancias, éstas sean superiores a aquella (tras unos años de cárcel, estaré en libertad con una fortuna que nunca hubiera conseguido honradamente); por eso es tan importante lograr que el corrupto devuelva a las arcas públicas todo lo conseguido ilícitamente.

De todas formas, cualquier solución a posteriori difícilmente logrará la completa restitución de lo defraudado, tanto porque lo primero que se defrauda es la confianza ciudadana-imposible de restituir-, como por la frecuencia con que los bienes materiales defraudados se habrán sustraído a la acción de los tribunales (situándolos en paraísos fiscales o por otro medio).

De ahí la importancia de la adopción de medidas profilácticas, preventivas, que dificulten (ya que no existe norma jurídica que la imposibilite) una actuación que, según señala la Comisión Europea ${ }^{21}$, se calcula que tiene un coste "para la economía de la Unión Europea (que) asciende a 120.000 millones de euros al año, algo menos que el presupuesto anual de la Unión Europea". Pues bien, en esta función preventiva un papel destacado corresponde al Derecho administrativo y, junto a él, a los Códigos éticos que, obviando expresamente los mandatos jurídicos, se centran en el respeto de unos valores que todos

${ }^{20}$ Esta idea es tributaria de la conferencia impartida el 15 de junio de 2015 por Antonio del Moral García, Magistrado de la Sala de lo Penal del Tribunal Supremo, en el curso sobre "La lucha contra corrupción política: herramientas del Estado y de la ciudadanía". Universidad del País Vasco/IVAP.

${ }^{21}$ Informe de la Comisión al Consejo y al Parlamento, de 3 de febrero de 2014, citado por Sala Sánchez, P., Discurso de investidura como Doctor "Honoris causa" por la Universidad de Valencia. Valencia, 26 de mayo de 2014, pg. 92. 
debemos compartir, pero que especialmente cuando son vulnerados por los responsables de la gestión pública derivan en supuestos de corrupción.

En el primer plano, el del Derecho administrativo -el que regula la relación de la Administración con los ciudadanos-, una exigente regulación de la contratación pública aplicada con rigurosidad y eficacia, de forma que se eviten tentaciones de "huidas del Derecho administrativo", constituye una importante traba a la corrupción. Del mismo modo, pese a que no siempre goce de popularidad, una adecuada articulación de la normativa urbanística y su escrupulosa aplicación, debería contribuir a erradicar la corrupción que demasiado a menudo ha estado relacionada en España con la construcción. Y es que, finalmente, los hechos han demostrado que la "burbuja inmobiliaria" no era un invento periodístico y que el descontrol urbanístico en muchos Ayuntamientos ha derivado en escándalos de corrupción que hoy se dilucidan ante los tribunales de justicia.

Otro campo, esencial, en el que se libra la batalla contra la corrupción política se sitúa en la normativa reguladora de la financiación y democratización interna de los Partidos Políticos. La posición central que los Partidos Políticos ocupan en nuestro sistema político (que permite su calificación como una partitocracia) hace que su correcta articulación condicione amplios sectores de la vida pública, incidiendo en el funcionamiento de prácticamente todas las instituciones. Importa, pues, y mucho, que una exigente regulación resuelva un tema que ha contribuido al divorcio de los ciudadanos de su clase política.

En la intersección entre el mundo del Derecho y el de la Ética se sitúan, en mi opinión, todos los esfuerzos destinados a materializar el Derecho al buen gobierno o a la buena administración (recogido como tal en el art. 41 de la Carta de Derechos Fundamentales de la Unión Europea), apareciendo el fomento de una buena gobernanza como una disposición de aplicación general en el artículo 15 del Tratado de Funcionamiento de la Unión Europea, del que son piezas claves el acceso a la información y la transparencia en la gestión. En esta línea se sitúan, dentro de España, entre otras, la Ley 5/2006 de 10 de abril, de regulación de los conflictos de intereses de los miembros del Gobierno y de los altos cargos de la Administración General del Estado o la Ley 19/2013, de 9 de diciembre, de transparencia, acceso a la información pública y buen gobierno, o, en el ámbito autonómico andaluz, la Ley 1/2014, de 24 de junio, de transparencia pública de Andalucía (BOJA núm. 124 de 30 de junio).

Y junto a estas medidas en las que, por la generalidad de los mandatos, la coercibilidad del Derecho empieza ya a diluirse, la otra vía para combatir la corrupción se encuentra, como indicaba, en los intentos de fortalecer la vigencia de los mandatos éticos. En principio, la exigencia de un comportamiento 
ético debe predicarse, como parte de una adecuada educación ciudadana, de todos sin excepción, formen parte de la Administración o sean simples ciudadanos. El problema es que, por su misma naturaleza, los comportamientos contrarios a la ética sólo pueden sancionarse en el mismo plano, ya que si de los mismos se hace derivar alguna consecuencia jurídica es porque previamente hemos conformado algún deber también jurídico.

Pues bien, es precisamente en este plano -el de la sanción- donde se puede matizar la anterior consideración ya que la responsabilidad especial que asumen los cargos públicos determina que se les pueda exigir con mayor rigor un comportamiento ético, poniendo en marcha Códigos de conducta que en sí mismos obedecen a un impulso ejemplarizante.

$\mathrm{Su}$ origen se encuentra en el mundo anglosajón, siendo por tanto ajenos hasta fecha reciente a la tradición de los países continentales europeos. De contenido normativo variable, lo que caracteriza a estos códigos es que no intentan regular conductas legalmente debidas, sino que lo que buscan es incidir sobre las convicciones éticas que deberán presidir la actividad de los responsables públicos. Así lo que estos códigos contienen es una llamada a la adecuación de la propia conducta a una serie de principios y valores que, por la generalidad con que se formulan, se pueden aplicar tendencialmente tanto a la actividad pública como privada de sus destinatarios.

Por escépticos que seamos sobre su capacidad conformadora de conductas y actitudes, lo cierto es que la OCDE ha incluido a los Códigos de Conducta dentro de la estrategia de lucha contra la corrupción en el sector público ${ }^{22}$. En España su aparición ha sido muy tardía y, con excepción de la experiencia en el País Vasco, a la que me referiré más adelante, de escasa repercusión. Así hay que esperar a la Orden del Ministerio de Administraciones Públicas, de 3 de marzo de $2005^{23}$, para que se apruebe un Código de buen gobierno de los miembros del Gobierno y de los altos cargos de la Administración General del Estado, en el que se reúnen una serie de "valores de referencia" que deben regir su actuación.

Estructurado en principios básicos, éticos y de conducta, el código presenta, en mi opinión, una doble debilidad. La primera tiene que ver con que su exigibilidad no descienda a las conductas individuales, sino que aparezca vinculada sólo a los "procedimientos y actuaciones" que pueden posibilitar su transgresión. Así se deduce del punto cuarto del Código de buen gobierno que dispone que "[a]nualmente el Consejo de Ministros conocerá un informe... sobre los eventuales incumplimientos de los principios éticos y de conducta

${ }^{22}$ Vid. en http://www.oecd.org/gov/ethicscodesandconductinoecdcountries.htm

${ }^{23}$ Orden APU/516/2005, de 3 de marzo, aprobada por Acuerdo del Consejo de Ministros de 18 de febrero de 2005. 
con el fin de analizar los procedimientos y actuaciones que pueden posibilitar su trasgresión y proponer las medidas que se estimen convenientes..."; la segunda, se vincula con un seguimiento de su aplicación poco efectivo, ya que se encomienda genéricamente al Ministerio de Administraciones Públicas, sin que se precisen las consecuencias de su vulneración, más allá de la inconcreta previsión de que el Consejo de Ministros, "en el supuesto de que hubiera incumplimientos de los principios del código, adoptará las medidas oportunas".

El texto ha sido derogado por la Ley $3 / 2015$, de 30 de marzo, reguladora del ejercicio del alto cargo de la Administración General del Estado. En este punto hay que destacar que el hecho mismo de la derogación por una Ley que impone obligaciones jurídicamente exigibles, de una Orden ministerial en que se recogen deberes éticos, resulta significativo de la existencia de una cierta confusión entre mandatos éticos y jurídicos. En distinto plano, la imperfección del mecanismo de seguimiento descrito se ha puesto de manifiesto precisamente con motivo de esa derogación. En efecto, cuando un parlamentario del PNV en el Congreso solicitó al Gobierno información detallada sobre los informes elevados al Consejo de Ministros durante los diez años en que la Orden estuvo en vigor y sobre las medidas adoptadas, en su caso, la respuesta del Ejecutivo resulta al menos perturbadora. Según sus términos,

“...no se ha elaborado ningún informe de los previstos en el apartado cuarto del Código de Buen Gobierno de los miembros del Gobierno y de los altos Cargos de la Administración General del Estado [...] dado que dicho documento sólo se elaboraría en el supuesto de un eventual incumplimiento de los principios éticos y de conducta de dicho Código. En consecuencia, al no haberse producido ninguno de esos incumplimientos no ha sido preciso elevar informe alguno en relación con ese Acuerdo" ${ }^{24}$.

Aparentemente la respuesta confunde "elaboración" de un informe con "adopción" de las medidas que, a la vista de las irregularidades detectadas en aquél, se estimen convenientes. Pero al margen de ello, creo que su contenido está llamado a producir desconcierto y frustración en una opinión pública cada vez más escéptica respecto de medidas que deberían garantizar la conducta ética de los responsables públicos, pero que terminan percibiéndose como "maquillajes" destinados a proporcionarles una imagen que les permita mantenerse en el poder. De este modo, iniciativas bien intencionadas destinadas a la regeneración de la vida pública, si no van acompañadas de medidas que garanticen su cumplimiento, no sólo van a demostrarse estériles, sino que pueden hacer aún más profundo el foso que separa a los cargos públicos de

${ }^{24}$ Solicitud de informe a la Administración del Estado Congreso (186/3583) de Aitor Esteban Bravo (GV), de 25/02/2015. (180880) 
los ciudadanos. Por ello, hay que buscar sistemas menos frágiles en que la integridad institucional se evalúe mediante controles objetivos.

\section{LA EXPERIENCIA DE LA COMUNIDAD AUTÓNOMA DEL PAÍS VASCO}

En este panorama nacional en que la misma naturaleza de los códigos de conducta resulta desdibujada, por la frecuente confusión de planos entre deberes éticos y deberes jurídicos, la Comunidad Autónoma del País Vasco presenta una trayectoria singular que merece ser objeto de análisis tanto en sí misma, como en relación con la precondición que la hizo posible.

La precondición a la que aludo no es otra que la unanimidad de las fuerzas políticas en la necesidad de que un Código ético añadiera a los compromisos políticos y jurídicos, las exigencias morales que requiere una sociedad democrática. Así lo prueba el hecho de que el antecedente inmediato del actual Código ético y de conducta del Gobierno Vasco lo constituya el Código de ética y buen gobierno que se incorporó al Acuerdo adoptado por el Consejo de Gobierno en la Resolución 23/2011, de 11 de mayo (BOPV 31 mayo 2011), es decir, cuando el Gobierno tenía distinto signo político al que tiene hoy.

A su vez, el actual Lehendakari en el discurso previo a su investidura, al trazar las líneas maestras de su futuro programa de Gobierno, apostó por la recuperación del sentido ético de la política, asumiendo un compromiso que se ha traducido en el vigente Código ético y de conducta, aprobado por el Consejo de Gobierno e incorporado como Anexo a la Resolución 13/2013, de 28 de mayo $^{25}$.

En paralelo, el Parlamento vasco ha avanzado también en la misma línea, a través de distintos proyectos y anteproyectos de leyes en los que ha venido trabajando desde la legislatura de 2005 a 2009, y que han culminado en la Ley $1 / 2014$, de 26 de junio, reguladora del Código de conducta y de los conflictos de intereses de los cargos públicos ${ }^{26}$.

Por tanto, ambos textos -el vigente Código de conducta aprobado por el Gobierno en 2013 y la Ley reguladora de 2014- han de ser tomados en consideración para fijar el estado de la cuestión en el ámbito de la Comunidad Autónoma. No obstante, a la espera de un ulterior desarrollo de la Ley nos centraremos en el análisis del contenido y aplicación del Código ético y de conducta del Gobierno Vasco.

1. El primer rasgo distintivo del Código ético y de conducta (en adelante CEC) lo constituye su carácter abierto y evolutivo. En efecto, el texto se con-

${ }^{25}$ BOPV de 3 de junio de 2013.

${ }^{26}$ Publicada en el BOPV de 1 de agosto de 2014. 
cibe como "un instrumento vivo y flexible", según se indica en su punto 1.4. Pues bien, la evolución que se anuncia puede obedecer, en principio, a dos posibles impulsos.

De una parte, el propio Código prevé su adecuación "de forma inmediata a las previsiones que establezcan las leyes del Parlamento Vasco en esta materia, siempre que entre éstas y aquéllos exista alguna discrepancia". Pues bien, no hay duda de que la citada Ley 1/2014 incide de forma directa sobre el Código que en el último párrafo de su Preámbulo aludía explícitamente a "la proposición de Ley que se encuentra en estos momentos en tramitación parlamentaria", autocalificándose como "un complemento de la legislación".

Por ello, desde la entrada en vigor de la Ley, la Comisión de Ética Pública, guardiana del Código a la que me referiré más adelante, ha incorporado a su argumentario lo dispuesto en la misma ${ }^{27}$. Y, lo que resulta aún más decisivo, el Gobierno Vasco ha extraído las consecuencias que se derivaban de la Ley, y ha adaptado al Código a sus previsiones. Así, por Acuerdo del Consejo de Gobierno de 17 de marzo de 2015, se ha modificado el ámbito de aplicación personal del Código ajustándolo a los términos señalados en la Ley y, además, se ha dado nueva redacción a su apartado 3.1, de tal forma que los destinatarios del Código no solo "deberán observar los valores, principios, conductas y comportamientos" del mismo, sino también "los expresados en los artículos 5, 6, 7 y 8 de la Ley $1 / 2014$ de 26 de junio".

La otra vía de evolución del Código se encuentra en las recomendaciones y propuestas que a tal efecto emita la Comisión de Ética Pública (en lo sucesivo, $\mathrm{CEP}$ ) en sus informes anuales. En la práctica, el único Informe presentado hasta la fecha (referido al período comprendido entre octubre de 2013 y julio de 2014) contiene varias recomendaciones que se han traducido en otras tantas modificaciones del Código, según lo dispuesto en el citado Acuerdo del Consejo de Gobierno.

Los cambios introducidos, a los que me referiré en el lugar que corresponda más adelante, no alteran sustancialmente ni el Código ni el funcionamiento de la Comisión, pero sí que resultan significativos en cuanto muestran la voluntad de adaptación a la realidad siempre cambiante, tanto del Código como de su principal instrumento de aplicación, la Comisión de Ética Pública.

La naturaleza del $C E C$ ha de partir de la propia denominación bifronte del Código. Bifronte porque, de una parte, se autodenomina Código ético, lo que supone que aspira a proyectarse hacia el interior de sus destinatarios exigiéndoles que asuman como propios los valores y principios que proclama;

${ }^{27}$ Concretamente, la primera vez que la Comisión invoca el contenido de la Ley es en el Acuerdo adoptado en el asunto 1/2015. 
estamos, aquí, ante lo que podemos calificar como la vertiente interna del CEC. Ahora bien, por otra parte, el Código al asumir que es un Código "de conducta" está requiriendo de esos mismos destinatarios que adecuen su comportamiento a los mismos: es la que podríamos calificar como vertiente externa del CEC. Así pues se puede hablar de la naturaleza dual del Código que es simultáneamente mandato ético y texto rector del comportamiento de sus destinatarios. Como señala la Memoria de la CEP, dado que "lo que el código pretende es recuperar la confianza de la ciudadanía en sus instituciones, carecería de sentido que se circunscribiera al terreno de las ideas y las opiniones, toda vez que el test ético que la sociedad aplica a los responsables públicos, no atiende tanto a las convicciones internas que guían la conducta, cuanto al sentido y el contenido material de sus actuaciones" ${ }^{28}$.

$\mathrm{Y}$ es que, el CEC nació con el designio expreso de "situar al Gobierno Vasco en la vanguardia de la defensa de la ética pública y de la integridad en el sector público del Estado, así como aproximar a la Comunidad Autónoma de Euskadi en esta materia con otros modelos comparados que son, sin duda, referencia obligada en el campo de la ética pública". Por ello no es un Código declarativo sin efectos reales, "puesto que si se acredita un incumplimiento se activa un sistema interno de seguimiento que puede terminar con el cese de la persona en el puesto de trabajo que ocupe o, en su caso, con la formulación de recomendaciones a los órganos competentes para que corrijan las desviaciones producidas".

El ámbito de aplicación personal del Código ético abarcaba, en principio, a los miembros del Gobierno, los altos cargos y asimilados, así como al personal directivo de las entidades del sector público y el personal eventual o de confianza de la Administración general e institucional del País Vasco. Así resultaba resumidamente de lo dispuesto en el apartado 2 del Código, que ha sido modificado por el Acuerdo de 17 de marzo de 2015, para alinearlo en lo posible con el definido en el artículo 2 de la Ley 1/2014.

Esta reforma amplía dicho ámbito personal de forma que ahora son también destinatarios del Código los dirigentes o administradores de entidades, de naturaleza y capital mayoritariamente privado, cuyo control corresponda a administraciones públicas o a sus respectivos sectores públicos, y que hayan sido designados por quienes están sometidos al propio Código. Del mismo modo se incluyen en su ámbito los titulares de la Presidencia y la Secretaría General del C.E.S.Vasco y del Consejo de Relaciones Laborales; el Director o Directora de la Agencia Vasca de Protección de Datos, los

${ }^{28}$ Memoria de la Comisión de Ética Pública del Gobierno Vasco (Octubre 2013 - Diciembre 2014). Instituto Vasco de Administración Pública, 2015, pág. 15 
miembros de la Comisión Jurídica Asesora de Euskadi y los del Órgano Administrativo de recursos contractuales de la Comunidad Autónoma del País Vasco.

Consideración especial merece la delimitación negativa del ámbito de aplicación del CEC a través de la consideración de quiénes se encuentran excluidos del mismo.

A la cabeza de este capítulo de exclusiones hay que situar a los destinatarios de la Ley 1/2014 a los que, sin embargo, no les resulta aplicable el CEC. En efecto, el catálogo de cargos públicos incluidos en el ámbito de aplicación de la Ley incluye al "ararteko" (Defensor del Pueblo) y a su adjunto o adjunta, así como a los miembros del Tribunal de cuentas y al titular de su Secretaría General. Por el contrario, ninguno de ellos aparece entre los destinatarios del Código.

La razón resulta evidente: el Parlamento, en el que reside el poder legislativo, dicta leyes que generan obligaciones de carácter general y que pueden perfectamente dirigirse a los cargos públicos que el propio Parlamento nombra. Por el contrario, el Gobierno, autor del Código ético, no puede vincular a cargos de extracción parlamentaria, según exige el principio de división de poderes. De ahí que incluso los Registros de actividades y de bienes, residenciados para los Altos Cargos del Poder Ejecutivo en la Dirección de Función Pública, se sustituyan respecto del Defensor del Pueblo y del Tribunal de Cuentas por Registros creados por los Servicios Administrativos del Parlamento (Disposición Adicional $3^{\mathrm{a}}$ de la Ley).

En segundo término, puesto que el ámbito de aplicación del CEC se delimita por referencia a los cargos públicos y asimilados, no puede sorprender que el personal funcionario y laboral no se vea afectado por sus disposiciones. Tantos unos como otros están sometidos a un estatuto jurídico propio sobre el que -siguiendo también en esto el ejemplo de los países anglosajones-, ni el Gobierno ni el Parlamento Vasco han querido incidir con nuevas exigencias éticas.

Por último, hay que hacer referencia a una exclusión, no por obvia menos llamativa. Y es que, el Código no resulta aplicable a los miembros del poder legislativo. Son varias las razones que la justifican. Habría, por una parte, una razón histórica, ya que es cierto que los códigos de conducta han nacido y se han desarrollado como tentativas de control del poder ejecutivo. Por otra parte, puesto que estamos ante textos elaborados originalmente por los Gobiernos, el principio de división de poderes determina que no vincule a los representantes de la soberanía popular.

Ahora bien, cuando el descrédito de la política y de los políticos afecta de manera nuclear a los Partidos Políticos, tal vez debería plantearse pro futuro -y ésta es una reflexión de carácter general que desborda a la Comunidad 
Autónoma del País Vasco- la conveniencia de que los propios Parlamentos adoptaran alguna medida similar en relación con los parlamentarios, miembros mayoritariamente de esos Partidos. No creo en fórmulas mágicas, pero tal vez de este modo se estableciera un puente que ayudara a salvar la brecha abierta entre los ciudadanos y sus representantes ${ }^{29}$.

En cuanto a su estructura, el Código ético se articula, de menor a mayor precisión, en torno a valores, principios y comportamientos. Los valores (integridad, excelencia, alineamiento entre política y gestión, liderazgo e innovación) constituyen tanto el objetivo último como el trasfondo sobre el que se proyectan las conductas que se quieren fomentar. Los valores integran así el enunciado de mayor generalidad que, por su nivel de abstracción, se erige en punto obligado de referencia en todo proceso de interpretación del Código.

En un nivel inmediatamente inferior desde la óptica de la generalidad, se encuentran los principios, perfectamente acordes con los valores, de los que, en realidad, representan un primer esfuerzo de concreción. Se trata de la imparcialidad y objetividad, de la responsabilidad por la gestión, de la transparencia y el gobierno abierto, de la honestidad y el desinterés subjetivo, del respeto y de la ejemplaridad. De su mero enunciado se deduce su carácter heterogéneo ya que, aunque la mayoría se refieren a actitudes y actuaciones individuales -predicables, por tanto, de la actividad de cada alto cargo sujeto al Código-, otros, como la transparencia y el gobierno abierto, sólo pueden cumplirse cabalmente en el seno de una organización administrativa que responda a esos mandatos. Ahora bien, incluso en estos casos el CEC traduce estos principios en comportamientos individuales insistiendo, por ejemplo, en el compromiso "de informar [a la ciudadanía] detalladamente sobre todas aquellas decisiones o actos que tengan implicaciones financieras".

Finalmente, el Código expone en detalle las conductas que se quieren favorecer y las que se quieren erradicar para alcanzar sus objetivos. Llegados a este punto, la precisión de los mandatos contenidos en el CEC es muy alta, traduciendo el esfuerzo porque se constituya en instrumento útil para valorar las acciones de sus destinatarios; este es, sin duda, un rasgo positivo del Código. No obstante, este mismo rasgo hace que el Código resulte exageradamente casuista, dificultando una exposición sistemática de su contenido.

${ }^{29}$ Un ambicioso Proyecto de Ley de integridad y ética pública que incluye en su ámbito de aplicación a los Diputados de las Cortes de Aragón fue aprobado por el Consejo de Gobierno de Aragón el 15 de diciembre de 2015. El texto, sometido a debate en las Cortes de la Comunidad Autónoma, prevé la creación de una Comisión Aragonesa de Integridad y Ética Pública con amplias competencias. Boletín Oficial de las Cortes de Aragón n 36 (IX Legislatura). 
Desde este concreto punto de vista -el de la enumeración de las conductas- la Ley 1/2014 presenta la ventaja de una articulación por los ámbitos en que las mismas se desarrollan -individual, institucional o en relación con la ciudadanía-, que permite una más rápida identificación y facilita una exposición ordenada.

En todo caso, aunque el esfuerzo de concreción resulta digno de encomio, hay que ser conscientes de que la realidad supera siempre la imaginación más desbordada, como mostraría la lectura de los Acuerdos de la Comisión de Ética Pública, de la que trataré a continuación.

En cuanto a los mecanismos de control dos son las vías complementarias que se prevé que lo transformen de loable declaración programática en texto vivo capaz de conformar la conducta de los altos cargos de la administración autonómica e institucional vasca.

De una parte, a través de la adhesión individual obligatoria el Código busca dotar de efecto vinculante a sus disposiciones. La obligatoriedad de la adhesión al Código supone una llamada de atención a todos los que ostentan hoy u ostentarán en el futuro un cargo en la administración vasca de que, al aceptar el nombramiento, aceptan el deber de adecuar su comportamiento a los principios, valores y conductas del Código. Y es que, la adhesión al Código se exige tanto a quiénes hubieran sido nombrados para el cargo con anterioridad a su adopción -con la consecuencia, si no se produjera, del cese inmediato-, como a quiénes lo sean con posterioridad, en cuyo caso la adhesión se materializará con carácter previo al nombramiento o toma de posesión.

La citada exigencia incluye el compromiso de presentar la dimisión en los supuestos en los que el incumplimiento suponga el cese (apartado 3.3). Por tanto aunque, se trata de un mecanismo de "auto-control", tiene consecuencias externas añadidas: por una parte, es requisito para que se perfeccione el nombramiento de los Altos Cargos, así como, en una primera etapa temporal, para el mantenimiento en el cargo ocupado con anterioridad a la adopción del Código; por otra, implica que sus destinatarios aceptan la obligación de presentar la dimisión si incurren en el incumplimiento del mismo.

Según se recoge en la primera Memoria de la Comisión de ética pública, en 2014, antes de que se ampliara el ámbito de aplicación personal del Código, la Declaración de adhesión había sido firmada por 231 personas. Cifra, ciertamente reducida, que ha de constituir punto de referencia obligado para evaluar la frecuencia con que se ha recurrido al mecanismo de "hetero-control" del Código.

Y es que, junto al examinado mecanismo de "auto-control", el CEC ha creado como sistema de "hetero-control" la Comisión de Ética Pública de la Alta 
Dirección Ejecutiva de la Administración General e Institucional de la Comunidad Autónoma de Euskadi, de la que vamos a ocuparnos a continuación.

2. La Comisión de Ética Pública (en lo sucesivo CEP). Por su naturaleza la CEP debe incluirse en el ámbito de la Administración consultiva del Gobierno Vasco. En efecto, con toda evidencia, la Comisión no participa de la función ejecutiva aunque sea un órgano creado por el poder ejecutivo. Por lo demás, implícita en esa naturaleza consultiva está el que en su actuación la Comisión goza de independencia funcional, en el sentido de que no recibe instrucciones del Gobierno, lo que, de producirse, arruinaría por completo su utilidad.

Independencia funcional que hay que mantener pese a su ubicación orgánica en la Consejería de Administración Pública y a una composición con fuerte presencia del Ejecutivo vasco. En concreto, la CEP está integrada por los titulares de la Consejería y Vice-consejería competente en materia de Administración Pública, por dos personas con experiencia y prestigio designadas por el Gobierno Vasco y por un alto cargo del Gobierno Vasco que asumirá la Secretaría y que tiene voz pero no voto. Se trata, por tanto, de un órgano eminentemente gubernamental, aunque la presencia en su composición de dos expertos independientes que igualan en número a los miembros del Gobierno vasco con voz y voto, la dotan de una presunción de imparcialidad que, a la luz de la experiencia, resulta confirmada en la práctica. Por otra parte, puedo asegurarles en primera persona, como uno de los expertos independientes que forman parte de la CEP, que lograr esa credibilidad ha sido una de las preocupaciones que han guiado la actuación de la CEP, en su conjunto, desde el primer momento.

Las funciones de la CEP pueden clasificarse en torno a las nociones de impulso, difusión y aplicación del Código de conducta aunque, sin duda, las funciones que mejor identifican la labor de la CEP son las referidas a su aplicación. Y es que, no sólo le corresponden de manera exclusiva, sino que además es el único órgano que, en el panorama de las Administraciones españolas, las tiene atribuidas. De manera complementaria, para garantizar el correcto cumplimiento del Código, la Comisión ha de proporcionar una interpretación de sus prescripciones que guie a sus destinatarios. Es precisamente en atención a estas últimas funciones por lo que entiendo que la CEP se configura cómo una auténtica guardiana del Código.

Así es tanto cuando resuelve las consultas que se le someten sobre la aplicación del Código, como cuando se pronuncia sobres las quejas o denuncias sobre su incumplimiento. Obsérvese que en ambos casos las conductas consideradas suelen ser básicamente las mismas, sólo que contempladas en un distinto momento: la consulta se realiza de forma preventiva, antes de realizar la 
acción que plantea la duda de su compatibilidad con el Código de Conducta; por el contrario, las quejas o las denuncias se producen cuando dicha acción se ha perfeccionado y alguien -incluso de manera anónima- señala a la CEP que el Código ha sido vulnerado.

Las acuerdos adoptados en uno y otro caso tienen en común que se basan en el análisis de la conducta que se pretende realizar o ya realizada, teniendo en consideración todas las circunstancias, para contrastarlas con los valores y principios del Código. Pues bien, esa labor de contraste entre conducta y norma exige la interpretación de la disposición de que se trate.

No obstante, el alcance del acuerdo necesariamente variará según estemos ante una consulta o ante una denuncia. Cuando se trata de consultas ex ante, la Comisión decidirá si la conducta que se pretende realizar se adecúa o no al Código; decisión que vinculará la actuación del cargo público concernido sea o no el autor de la consulta, dado que, por hipótesis, tiene que haber suscrito su adhesión personal al Código. Por su parte, cuando se trate de denuncias o quejas ex post sobre acciones ya realizadas, si el Acuerdo de la CEP es que no se ha conculcado el Código, con él se cierra el caso. Por el contrario, si la Comisión estima que la acción en cuestión lo ha violado se abre una segunda fase, en la que las consecuencias de tal constatación se encuentra condicionada por las competencias de la Comisión.

Las competencias de la CEP se traducen en la propuesta al órgano competente de una de estas dos opciones: el cese inmediato de la persona o personas implicadas, o, la adopción de otras medidas de carácter no sancionador, que resulten proporcionadas a los hechos acreditados. Hay que señalar que la introducción de esta segunda posibilidad se debe a una propuesta de la propia Comisión en su Informe anual, después de que en un caso concreto concluyera que se había vulnerado el Código, viendo limitada su facultad de propuesta a la del cese del cargo público concernido. En principio, mi juicio sobre la reforma introducida tiene que ser favorable, dado la importancia del principio de proporcionalidad en el plano ético.

En segundo término, en los supuestos en que los hechos acreditados pudieran ser constitutivos de delito, falta o infracción administrativa, la Comisión dará traslado del asunto, según proceda, al Ministerio Fiscal (a través del órgano competente de la Administración autonómica) o al órgano administrativo competente para la instrucción del expediente disciplinario que proceda por la infracción eventualmente cometida.

De lo anterior se deduce que, en principio, todas estas competencias se predican de las conductas individuales, públicas o privadas, de los cargos públicos. Ahora bien, también resulta claro que la vida pública no es sólo la resul- 
tante de estas conductas, sino que a su configuración contribuye de manera decisiva el funcionamiento de las instituciones y de los distintos departamentos administrativos en que se integran. Por eso una parte significativa tanto de la Ley como del Código está consagrada a la gestión que ha de ser responsable, transparente y eficaz. En otras palabras, hay que incluir entre los deberes éticos de los cargos públicos la procura del buen gobierno que los ciudadanos esperan y que les hará confiar en la política y los políticos. Pues bien, cuando esto no ocurre sin que sea posible atribuir el fallo funcional a cargos públicos concretos, el único instrumento puesto al servicio de la CEP es la de recomendación que se enuncia, en términos muy amplios y generales en el apartado 16.3 del Código como una de sus funciones (aunque en mi propio esquema yo la sitúe como una competencia), El punto concreto señala que la CEP puede "Plantear recomendaciones a los cargos públicos y asimilados, así como a los departamentos y entidades, sobre el cumplimiento del Código Ético y de Conducta".

Competencia genérica que se refiere tanto a los cargos públicos individualmente considerados como al funcionamiento de las instituciones a las que sirven, dos planos que, incluso, se funden cuando (en el marco del principio de ejemplaridad) los actos, actuaciones o hechos de los primeros tienen "consecuencias directas sobre el deterioro de la imagen institucional ante la ciudadanía y afectan a la reputación de la propia institución". Y es que en tales casos la recomendación puede ser un complemento necesario de la medida que proceda respecto a uno o varios cargos públicos; del mismo modo que cuando el deterioro institucional no tenga un responsable directo perfectamente individualizable, las recomendaciones de la CEP para mejorar el funcionamiento institucional deben contribuir a la implantación de valores y principios éticos cuya aplicación práctica suscita dudas.

En su funcionamiento la CEP utiliza habitualmente medios telemáticos. Así se preveía ya en la redacción original del Código que sólo exigía que se reuniera, como mínimo, dos veces al año -y así lo hizo en 2014-; exigencia que a propuesta de la Comisión se ha reducido a una, aunque se prevea también la celebración de cuantas reuniones extraordinarias se estimen necesarias. En suma, y salvo que haya que recurrir a esta cláusula de cierre, lo normal es que la Comisión siga utilizando en su funcionamiento ordinario medios telemáticos que han demostrado sobradamente su eficacia. De este modo la reunión anual se consagrará normalmente a la discusión del proyecto de Memoria a elevar al Consejo de Gobierno, con especial énfasis en las recomendaciones que contribuyan a mejorar la difusión, interpretación y aplicación del Código Ético.

Como señalaba, cualquier valoración de la actividad de la CEP debe tener en cuenta el "universo" sobre el que se aplica, que no alcanza las 300 perso- 
nas. Ello explica que su volumen no sea excesivo: 14 Acuerdos corresponden a 2013, 10 a 2014 y 13 en 2015. Parece, pues, que la estadística muestra una tendencia a consolidarse en torno a las doce consultas anuales, lo que supone sin duda un buen porcentaje, que podría disminuir a medida en que el cuerpo de doctrina fijado por la Comisión, contribuya a desvanecer las dudas que puedan plantearse a los destinatarios del Código de Conducta.

Todos los acuerdos adoptados por la Comisión se hacen públicos en la página web de la Consejería de Administraciones Públicas, en la que se puede comprobar que grosso modo en dos tercios de las consultas la CEP ha entendido que no había contravención del CEC, mientras que en el tercio restante se ha recomendado la abstención o renuncia, al existir una posible contravención del Código. Sin que falte algún ejemplo en el que, a un pronunciamiento de compatibilidad, se ha unido una recomendación de abstención, en aras del principio de ejemplaridad. Finalmente, en un caso, la apreciación de que se había vulnerado el Código fue seguida del cese del Alto Cargo implicado.

\section{A MODO DE COLOFÓN}

Para concluir, permítanme que insista en una idea que ha planeado sobre toda mi exposición, seguidas de unas reflexiones personales que realizo con la vista puesta en el futuro.

A. La primera es que estamos ante una experiencia inédita en el panorama de las Administraciones públicas del Estado español, lo que nos priva de cualquier punto de referencia para juzgar de su éxito o fracaso. Así el juicio al respecto ha de ser necesariamente absoluto, sin elementos externos de comparación. Y situados en ese plano mi valoración es inequívocamente positiva: la asunción del Código ético por los cargos públicos a los que va destinado merece un juicio positivo. De hecho, las consultas que se someten a la Comisión muestran un grado de auto-exigencia que se corresponde perfectamente con la función profiláctica que tienen Código y Comisión.

Por otra parte, cabe entender que las denuncias ante la Comisión prueban que los ciudadanos empiezan a ver en ella un instrumento útil para sanear la vida pública. El que algunas denuncias sean anónimas parece evidenciar una cierta desconfianza en las estructuras del Estado de Derecho. Un dato que, sin duda, es negativo, pero que al mismo tiempo mostraría que el denunciante conserva un margen de confianza en la CEP cuando busca activar su funcionamiento. Desgraciadamente el deseo de mantener el anonimato suele traducirse en la falta de precisión de las denuncias que, por ello, difícilmente permiten apreciar la existencia de vulneraciones del Código de Conducta. 
En tercer lugar, el éxito de una iniciativa puede medirse también por su capacidad para incidir en el entorno, arrastrando a otros sujetos ajenos, en principio, a su ámbito. Y eso es lo que está ocurriendo con el CEC y la CEP. Como he dicho, su ámbito de aplicación se concreta a la Administración del Gobierno autonómico, lo que excluye, por tanto, las otras administraciones coexistentes en el País Vasco, entre ellas las Diputaciones Forales en cuya importancia, histórica y como centro de poder, no resulta necesario insistir, y los Ayuntamientos.

Pues bien, la Diputación Foral de Alava-Araba, en septiembre de 2015, ha aprobado un Código de ética y buen gobierno para los cargos públicos y representantes del sector público ${ }^{30}$, en el que se contemplan Comisiones de aplicación con dos miembros externos a la Diputación Foral. A su vez, la Diputación Foral de Guipúzcoa, tras aprobar un Documento por una Gobernanza ética, va a implantar un Sistema de integridad institucional ${ }^{31}$ en el que se inserta, como pieza nuclear, un Código de conducta y buenas prácticas de los cargos públicos forales, en el que está prevista la existencia de órganos de garantía, concretamente de una "Comisión de ética institucional", con cometidos similares a los asignados a la CEP y con una composición que refuerza el carácter externo del control ejercido al cifrarse en tres el número de los vocales ajenos a la administración foral.

Por su parte el Ayuntamiento de Bilbao ha aprobado también un Código de conducta, buen gobierno y compromiso con la calidad institucional ${ }^{32}$, que instituye una Comisión de ética y buen gobierno en la que también figuran dos miembros externos.

De este modo, de manera paulatina parece abrirse paso la idea de que el cambio a mejor de la imagen pública de los políticos pasa porque asuman mayores responsabilidades éticas, en contrapartida por el mayor poder depositado en sus manos. Ciertamente no es la solución de todos los problemas de una sociedad a la que le duele especialmente la corrupción y la mala gestión, pero sí que es la ruptura con el inmovilismo o la judicialización de la vida política que tanto daño están causando a nuestro sistema democrático.

B. En segundo lugar, quiero concluir con una serie de reflexiones personales en dos planos distintos que solo tienen en común el convencimiento de que en la lucha contra la corrupción hay que trascender el planteamiento exclusivamente individualista, aun reconociendo que éste es imprescindible. De hecho a la lucha

${ }^{30}$ Acuerdo 144/2015, de 3 de septiembre (BOTHA n ${ }^{\circ} 107$ de 11 de septiembre de 2015).

${ }^{31}$ El Sistema de integridad institucional de la Diputación foral de Guipúzcoa y de su sector público, lleva fecha de 1 de marzo de 2016.

${ }^{32}$ Acuerdo de Pleno de 24 de noviembre de 2015. 
contra la corrupción, entendida como lucha contra los corruptos, se encaminan todas las medidas que hemos examinado, desde las sancionadoras hasta las profilácticas. Todas son necesarias, aunque no creo que sean suficientes.

a) Por una parte, no hay que olvidar que los altos cargos, los políticos en general, no pertenecen a ninguna "casta" especial que se desarrolla al margen de la sociedad que los elige y los juzga después, a veces muy duramente. Los políticos, de cuya corrupción nos hemos ocupado, forman parte de esa misma sociedad y tienen, como regla general, sus mismas virtudes y sus mismos vicios. Por eso, si queremos potenciar la lucha contra la corrupción hemos de insistir en la importancia de la batalla que se libra en las escuelas $\mathrm{y}$ en los medios de comunicación. En las escuelas porque es en ellas donde se empieza a edificar la conciencia ciudadana que debería construirse a partir de una educación en valores que ayude a levantar barreras frente a la cultura que entroniza, como a un dios, al éxito económico. Parafraseando la Constitución de la UNESCO cuando dice que "puesto que las guerras nacen en la mente de los hombres, es en la mente de los hombres donde deben erigirse los baluartes de la paz", podríamos afirmar que también es en la mente de los hombres donde han de enraizarse los valores éticos que liberen a una sociedad intoxicada por mensajes en que la honradez se presenta demasiado a menudo como propia de la moral de los "perdedores", de los "fracasados".

Por lo demás, en atención al origen de tales mensajes, resulta necesario también hacer una llamada a la colaboración de los medios de comunicación, decisivos en la formación de la conciencia de la sociedad. Hoy menos que nunca la educación se recibe solo en las aulas, los "medios" -la prensa, la radio, la omnipresente TV- influyen mucho en la percepción que tenemos de la realidad. Pues bien, con pleno respeto de la libertad de expresión, hay que mandar un mensaje a los profesionales que los integran para que sean conscientes de la importancia decisiva de su labor en la lucha contra la corrupción que todos decimos combatir. La sordidez de las conductas de los corruptos no puede enmascararse como si habláramos de triunfadores a los que la suerte, la fortuna, les dio la espalda en un momento determinado, cuando su conducta se puso al descubierto.

Insisto en la idea: los políticos corruptos no se han generado en un mundo ajeno al que vivimos; por el contrario, son nuestros familiares, nuestros vecinos, nuestros conciudadanos los que, en ciertas circunstancias, han antepuesto su interés al interés general que decían servir. Luchemos en todos los frentes para que la sociedad a la que pertenecen no avale de ninguna manera conductas que nos avergüenzan. 
b) Mi segunda reflexión personal tiene también que ver con la inevitable vertiente colectiva de la corrupción, en sentido lato, en la que debemos profundizar si queremos avanzar en la vía emprendida. En efecto, no puede bastarnos con que el compromiso de los cargos públicos se refiera solo a que su conducta personal obedezca a los intereses generales, hemos de luchar también para que su gestión al frente de cada departamento, de cada órgano, de cada institución, responda a los mandatos éticos de eficacia, ejemplaridad y respeto a los ciudadanos. Esta es una vía de mayor exigencia que entiende incluido en el compromiso ético de los cargos públicos el correcto funcionamiento de los servicios públicos de su responsabilidad. En esta línea avanza con prudencia la CEP del Gobierno vasco, por ejemplo en su Acuerdo $2 / 2016$, de 8 de febrero. En el caso, planteado a raíz de una denuncia, la Comisión no advierte que los cargos públicos cuestionados hayan vulnerado el Código ético, aunque constata el defectuoso funcionamiento del servicio, lo que le lleva a recordar que los mandatos de la Ley del Parlamento vasco y el propio Código "relacionados con el liderazgo, la excelencia y el alineamiento entre la política y la gestión, obligan a los cargos públicos bajo cuyo ámbito de responsabilidad se han detectado las deficiencias organizativas, relacionales y de funcionamiento... a implicarse personalmente en procurar su resolución" ${ }^{\prime 3}$.

Hasta la fecha, la CEP no ha extraído ninguna consecuencia de esta constatación. Y es que, el tema es delicado porque para avanzar por esa vía resulta necesario determinar quiénes son responsables del mal funcionamiento de un concreto servicio público, algo que puede ser complejo ya que en muchos casos la relación causa/efecto resultará difusa. Sin embargo, la dificultad no debe ser excusa para la inacción. Así una vez que se asiente firmemente el principio habrá que trabajar para despejar las incógnitas que se nos plantean. Creo que la recompensa merecerá la pena, porque si lo logramos habremos dado un paso más en la lucha contra la corrupción. Una lucha que si la percibiéramos como un camino tendría la peculiaridad de que en él cada logro que se alcanza es tan importante como llegar a la meta... que se aleja necesariamente a medida que la sociedad profundiza en sus exigencias, en sus compromisos éticos. De este modo podríamos decir que, en cierto sentido, en la lucha contra la corrupción el camino es la meta, el medio es el fin. Por eso lo determinante es que una sociedad, una administración, un país se encuentren en esa vía, en la que ha de situarse España si queremos que la corrupción sea sólo el recuerdo bochornoso de una etapa oscura de nuestra historia.

\footnotetext{
${ }^{33}$ Punto 26 del Acuerdo 2/2013 que se recuerda en el punto 6 de su parte dispositiva.
} 


\section{BIBLIOGRAFÍA}

F. Balaguer Callejón, "Crisis económica y crisis constitucional en Europa", Revista Española de Derecho Constitucional, núm 98, mayo-agosto (2013).

G. Camara Villar, "Crisis económica y Constitución". Libro-Homenaje al profesor Carlos de Cabo. Ed. Tirant lo blanc. Valencia, 2015.

J. Lladós Vila y T. Freixas, The impact of the crisis on fundamental rights across Member States of the EU. Country Report on Spain, 30 de junio de 2004 (http:// www.europarl.europa.eu/studies)

Memoria de la Comisión de Ética Pública del Gobierno Vasco (Octubre 2013 - Diciembre 2014). IVAP, 2015

Ohchr, Report of the United Nations High Commissioner for the Human Rights: Austerity measures and economic, social and cultural rights, 2013 (www.ohchrorg/ Documents/Issues/Development/Rightscrisis/E-2013 - 82)

J. M. Pureza, Linhas Vermelhas. Crítica da crise-como-politica. Bertrand Editora. Lisboa, 2015.

P. Sala Sánchez, Discurso de investidura como Doctor "Honoris causa" por la Universidad de Valencia. Valencia, 26 de mayo de 2014. 